\title{
DNA Metabarcoding Reveals Dietary Network Structure in a Neotropical Bat Community
}

\author{
Melissa Ingala ${ }^{1}$, Nancy Simmons ${ }^{2}$, Claudia Wultsch ${ }^{2}$, Konstantinos Krampis ${ }^{3}$, Kaiya \\ Provost $^{1}$, and Susan Perkins ${ }^{2}$ \\ ${ }^{1}$ Richard Gilder Graduate School \\ ${ }^{2}$ American Museum of Natural History \\ ${ }^{3}$ Hunter College, City University of NY
}

October 11, 2020

\begin{abstract}
Bat communities in the Neotropics are some of the most diverse assemblages of mammals on Earth, with some regions supporting more than 100 sympatric species. This diversity raises the question of how so many species can coexist without apparently competing for resources. Because bats are small, nocturnal, and volant, it is difficult to directly observe their feeding habits, which has resulted in their classification into broadly defined dietary guilds (e.g. insectivores, carnivores, frugivores). Apart from these broad guilds, we lack detailed information about what bats eat and therefore have only a limited understanding of interaction networks linking bats and their arthropod, plant, and vertebrate prey. In this study, we used DNA metabarcoding of plants, arthropods, and vertebrates to infer the diets of 25 species of bats from the tropical dry forests of Lamanai, Belize. We hypothesized that bat diets recovered by metabarcoding would show a more granular structure than implied by the broad guilds to which species have been traditionally assigned. Our results indicate that bat communities from Lamanai can be organized into eight distinct sub-community modules and that bats partition food resources on a finer scale than previously recognized. This study is the most comprehensive treatment to date of Neotropical mammal diets at the community level, and provides a useful framework for testing hypotheses about coexistence and niche differentiation in the context of modern high-throughput molecular data.
\end{abstract}

\section{Hosted file}

Ingala_etal_MolecEcol10.pdf available at https://authorea.com/users/332920/articles/486121dna-metabarcoding-reveals-dietary-network-structure-in-a-neotropical-bat-community 